\title{
Prognostic and predictive markers in recurrent high grade glioma; results from the BR12 randomised trial
}

Vincent Peter Collins ${ }^{1,5^{*}}$, Koichi Ichimura ${ }^{1,4}$, Ying Di ${ }^{1}$, Danita Pearson ${ }^{1}$, Ray Chan ${ }^{1}$, Lindsay C Thompson ${ }^{2}$, Rhian Gabe ${ }^{2}$, Michael Brada ${ }^{3}$, Sally P Stenning ${ }^{2}$ and on behalf of the BR12 Collaborators

\begin{abstract}
We evaluated the prognostic and predictive value of a range of molecular changes in the setting of a randomised trial comparing standard PCV (procarbazine, CCNU (1-(2-chloroethyl)-3-cyclohexyl-1-nitrosourea) and vincristine) chemotherapy with the standard temozolomide (TMZ) 5 -day ( $200 \mathrm{mg} / \mathrm{m}^{2} /$ day) schedule and a 21 -day $\left(100 \mathrm{mg} / \mathrm{m}^{2} /\right.$ day) schedule in chemo-naïve, high-grade glioma (non-oligodendroglial tumours; WHO (World Health Organisation) grades III and IV) patients at first progression following radiotherapy.

354 samples (79.2\%) from the first operation of the 447 randomised patients provided enough tumour DNA for some or all parts of the study. Genome-wide array comparative genomic hybridisation (aCGH), mutation analysis of IDH1/2 and TP53 and methylation analyses of the MGMT CpG-island was done.

$84 \%$ of grade III tumours and $17 \%$ of grade IV had IDH1 or IDH2 mutations that conferred a better prognosis in both; MGMT methylation (defined as average value across $16 \mathrm{CpGs} \geq 10 \%$ ) occurred in $75 \%$ of tumours and was also associated with improved survival. Both were of independent prognostic value after accounting for clinical factors and tumour grade. None of the molecular changes investigated gave clear evidence of a predictive benefit of TMZ over PCV or 21-day TMZ over 5-day TMZ although power was limited and a role for MGMT methylation could not be ruled out. Loss of $1 p$ and $19 q$ was seen in only 4 patients although hemizygous loss of 1 p36 occurred in $20 \%$.

The findings support reports that IDH1/2 mutations and MGMT methylation can be used in addition to tumour grade and clinical factors to predict survival in patients with recurrent high grade gliomas when treated with any of the therapy regimes used.
\end{abstract}

Keywords: Anaplastic astrocytoma, Glioblastoma, MGMT, IDH1, IDH2, Genetic analysis

\section{Introduction}

Randomised clinical trials provide a basis for successful evaluation of biomarkers. To date methylation of the $\mathrm{O}^{6}$ methylguanine-DNA methyltransferase (MGMT) gene is the only molecular marker that can be mechanistically linked to a response to alkylating agent chemotherapy. $M G M T$ promoter methylation with resultant decreased expression of the protein product, is believed to compromise

\footnotetext{
* Correspondence: Vpc20@cam.ac.uk

'Department of Pathology, Division of Molecular Histopathology, University

of Cambridge, Cambridge, UK

${ }^{5}$ Department of Histopathology, Addenbrooke's Hospital, Cambridge CB2 2QQ, UK

Full list of author information is available at the end of the article
}

the repair of DNA damage caused by alkylating agents. In an EORTC trial of temozolomide in the primary treatment of glioblastoma [1] MGMT methylation status was strongly prognostic for survival, and with a suggestion of a predictive effect [2] although this remains unproven within that trial. Other studies [2,3] have also shown MGMT methylation to be prognostic in glioblastoma patients given chemoradiotherapy $[4,5]$. More recently studies in elderly and poor prognosis patients with glioblastoma testing chemotherapy alone against radiotherapy with or without chemotherapy demonstrated predictive value of MGMT methylation status (Wick et al. [5] (NA08), Malmstrom et al. [6]). On current evidence the predictive value appears confined to this patient population. However, the value of

\section{Ciomed Central}

(c) 2014 Collins et al.; licensee BioMed Central Ltd. This is an Open Access article distributed under the terms of the Creative Commons Attribution License (http://creativecommons.org/licenses/by/4.0), which permits unrestricted use, distribution, and reproduction in any medium, provided the original work is properly credited. The Creative Commons Public Domain Dedication waiver (http://creativecommons.org/publicdomain/zero/1.0/) applies to the data made available in this article, unless otherwise stated. 
MGMT methylation has not been tested in patients treated with PCV (Procarbazine, CCNU and Vincristine), a recognised effective regimen in the treatment of recurrent high grade glioma used as standard therapy prior to the introduction of temozolomide. While both Procarbazine, and CCNU are also alkylating agents, it is possible that $M G M T$ methylation status might be differentially predictive of response to temozolomide over PCV.

We therefore evaluated the prognostic and predictive value of a range of molecular changes reported for adult brain tumours in the setting of a randomised trial in chemo-naïve, recurrent high-grade astrocytic gliomas (WHO grades III and IV) including anaplastic astrocytoma (AA), anaplastic oligoastrocytoma (AOA), glioblastoma (GB) and gliosarcoma (GS) following previous radiotherapy, comparing PCV (procarbazine, CCNU and vincristine) chemotherapy with two temozolomide schedules; the standard 5-day (200 mg/m²/day) schedule and a 21-day $\left(100 \mathrm{mg} / \mathrm{m}^{2} /\right.$ day $)$ schedule. The results of this trial have been published elsewhere [7]. The molecular characteristics of the tumours analysed included 1p and 19q copy number status, originally considered a prognostic marker in oligodendroglial tumours but more recently shown to be predictive in patients with anaplastic oligodendroglioma [8,9], MGMT copy number and methylation status and $I D H 1$ or $I D H 2$ mutation, all reported to be prognostic biomarkers [1,2,10-12]. In addition other genetic abnormalities frequently reported in these tumour types were also analysed. The sub-randomisation between 5-day and 21-day schedules in this trial also provided a framework for the investigation of the hypothesis that higher intensity of temozolomide treatment might be required for a response, if one or two unmethylated copies of the MGMT gene are present.

\section{Materials and method Patients}

Patients were drawn from the 447 patients with recurrent high grade glioma randomised into the MRC BR12 trial [7] who consented to the use of their formalin fixed paraffin embedded tumour samples for central review and further research. The trial was ethically approved and written informed consent was obtained from all patients. Eligible patients for the trial were chemo-naive adults of either sex with histologically verified AA, GB, AOA or GS (WHO grade III/IV at diagnosis, relapse or transformation) who had undergone primary treatment including radiotherapy completed $>2$ months before randomisation, had evidence of progression confirmed by evaluable enhancing recurrent tumour on contrast enhanced MRI/CT within the 2 weeks prior to start of treatment, and were considered fit for chemotherapy. A central review of pathology data followed the 4th edition of the WHO Classification of Tumours of the Central Nervous system [13].

\section{Tumour tissue}

Tumour tissue was required from the first diagnosis of a high grade tumour and was 'micro-dissected' from sections from the blocks taken at the time of the original surgery in most cases. In a small number of cases blocks were also available from diagnostic material resected at recurrence. The commonest cause of a case failing the molecular analysis was the available tissue blocks consisting of few well-preserved tumour cells with widespread necrosis.

\section{DNA isolation and genome-wide copy number analysis}

Tumour DNA was isolated using QIAamp DNA micro kit (Qiagen, Cat 56304) from micro-dissected (often multiple) $10 \mu \mathrm{m}$ sections from the paraffin blocks of each case avoiding normal tissue and necrosis. Genome wide copy number data was obtained by array comparative genomic hybridization using a custom tiled path array of chromosome 1 and 19 incorporated into a $1 \mathrm{Mb}$ genome-wide array with additional probes for genes of interest as previously described $[14,15]$. The copy number status of the following regions were scored for statistical analyses: Chromosome 1 (particularly total 1p loss and localised 1p36 loss), chromosome 7, chromosome 10, chromosome 13, and chromosome 19 (particularly total 19q loss). Genes of particular interest where copy number was reported separately included EGFR, CDKN2A/B and $p 14^{A R F}$, MDM2, CDK4, RB1 and PDGFRA, PTEN and MGMT.

\section{Mutation analysis of IDH1, IDH2 and TP53 and MGMT methylation analysis}

Pyrosequencing of exon 4 of $I D H 1$ was done and if no mutation was found exon 4 of $I D H 2$ was also pyrosequenced [16]. The PCR primers used were as follows: IDH1 Forward primer CAAAAATATCCCCCGGCTTG, with reverse primer bio-CAACATGACTTACTTGATC CCC and for IDH2 ACATCCCACGCCTAGTCCC with reverse primer bio-TCTCCACCCTGGCCTACCTG. Single stranded templates were prepared using a PyroMark Vacuum Prep Workstation (Qiagen, Crawley, UK) as per manufacturer's recommendations. Briefly $40 \mu \mathrm{l}$ of the PCR product was mixed with $3 \mu$ l of Streptavidin Sepharose Beads (GE Healthcare, Little Chalfont, UK) and $37 \mu \mathrm{l}$ of Binding buffer (Qiagen, Crawley, UK) binding the biotinylated DNA to the sepharose beads followed by denaturation and the removal of the non-biotinylated strand and annealing to 1.5 picomole of the pyrosequencing primer in the annealing buffer (Qiagen, Crawley, UK). The pyrosequencing primer for IDH1 was TGGGTAAAACC TATCATCATA and for IDH2 CCAAGCCCATCACCA TTG. Pyrosequencing was performed using PyroGold SNP Reagents and PyroMark software on a PyroMark ID pyrosequencer (Qiagen, Crawley, UK) as recommended. The system interrogated the 1st (c.394) and 
2nd (c.395) nucleotides of codon 132 (Arg) in IDH1 and the 1st (c.514) and 2nd (c.515) nucleotides of codon 172 (Arg) in $I D H 2$.

TP53 mutation analysis [17] was carried out by individual PCR amplification of each of exons 4 to 10 followed by direct sequenceing using the Applied Biosystems BigDye Terminator v3.1 cycle sequencing Kit (Life Technologies) on an ABI PRISM 3100-Avant Genetic Analyser (Life Technologies) [18].

Methylation analysis of the MGMT promoter was by bisulfite modification of approximately $500 \mathrm{ng}$ genomic DNA using the EZ DNA Methylation Kit (ZYMO Research, Orange, CA 92867 U.S.A., Cat D5001) followed by PCR using a forward primer GTTTYGGATATGT TGGGATAG and a biotinylated reverse primer bio-AAA ACCACTCRAAACTACCAC in a $50 \mu \mathrm{l}$ reaction including $2.5 \mathrm{mM} \mathrm{MgCl}_{2}, 250 \mu \mathrm{M}$ each dNTP and 1.25 units of Thermo-Start DNA polymerase (Thermo Scientific, Loughborough, UK) for map of region see Figure 1. Amplification of the 166 bp product was confirmed by agarose gel electrophoresis. Single stranded templates were prepared as described above for the IDH1/2 mutation analysis. Two assays were run on this template using the following two pyrosequencing primers: GATA GTTYGYGTTTTTAGAA to analyze, YGTTTTGYGTT TYGAYGTTYGTAGGTTTTYGYGGTGYGTATYGTT TGYGA, dispensation order ATCGTTAGTCTGTTC GTATCAGTCGTCATGTTCAGTCGTAGTCGTGATCG TAGTCG; and GYGATTTGGTGAGTGTTTG to analyze, GGTYGTTTYGTTTTYGGAAGAGTGYGGAGTTTTT TTTYGGGAYGG, dispensation order AGTCTGTTC AGTTCGAGAGTAGTCGATGCTTCGTATC. PyroGold Q96 SQA reagents and the PyroMark ID pyrosequencer
(Qiagen, Crawley, UK) were used and the data were analyzed using Pyro Q-CpG software reporting\% methylation at each of the 16 CpGs [19,20]. This analysis encompasses all MSP CpGs as studied by Stupp et al. and Hegi et al. [1,2].

\section{Statistical methods}

Associations between markers and clinical variables were quantified using the $\chi^{2}$ test of association or Fisher's exact test for categorical variables, and t-test to compare mean age across different types of abnormalities. The primary outcome measure for assessment of prognostic and predictive markers was survival, calculated from the date of randomisation into the main trial to the date of death, or date last known to be alive. Sample size was dictated by the availability of samples in trial patients, but conservative a priori sample size calculations based on obtaining samples for 235 patients (with 213 events) would give over $80 \%$ power to detect a hazard ratio of 0.6 for a marker with $50 \%$ prevalence at a 2 -sided significance level of $1 \%$. Kaplan-Meier survival curves were compared using the log rank test and potential prognostic markers were fitted into a Cox regression survival model containing baseline clinical characteristics (age, gender, tumour grade (AA vs $\mathrm{GB})$, and WHO performance status) to look for evidence of independent prognostic importance. $\mathrm{X}^{2}$ tests for heterogeneity were used to assess evidence that marker status was predictive of treatment effect (TMZ vs PCV and 5-day TMZ vs 21-day TMZ acknowledging that power for the latter comparison was substantially reduced), or showed evidence of interaction with tumour grade.

MGMT methylation was initially averaged across all 16 CpGs and considered as a binary variable as in previous

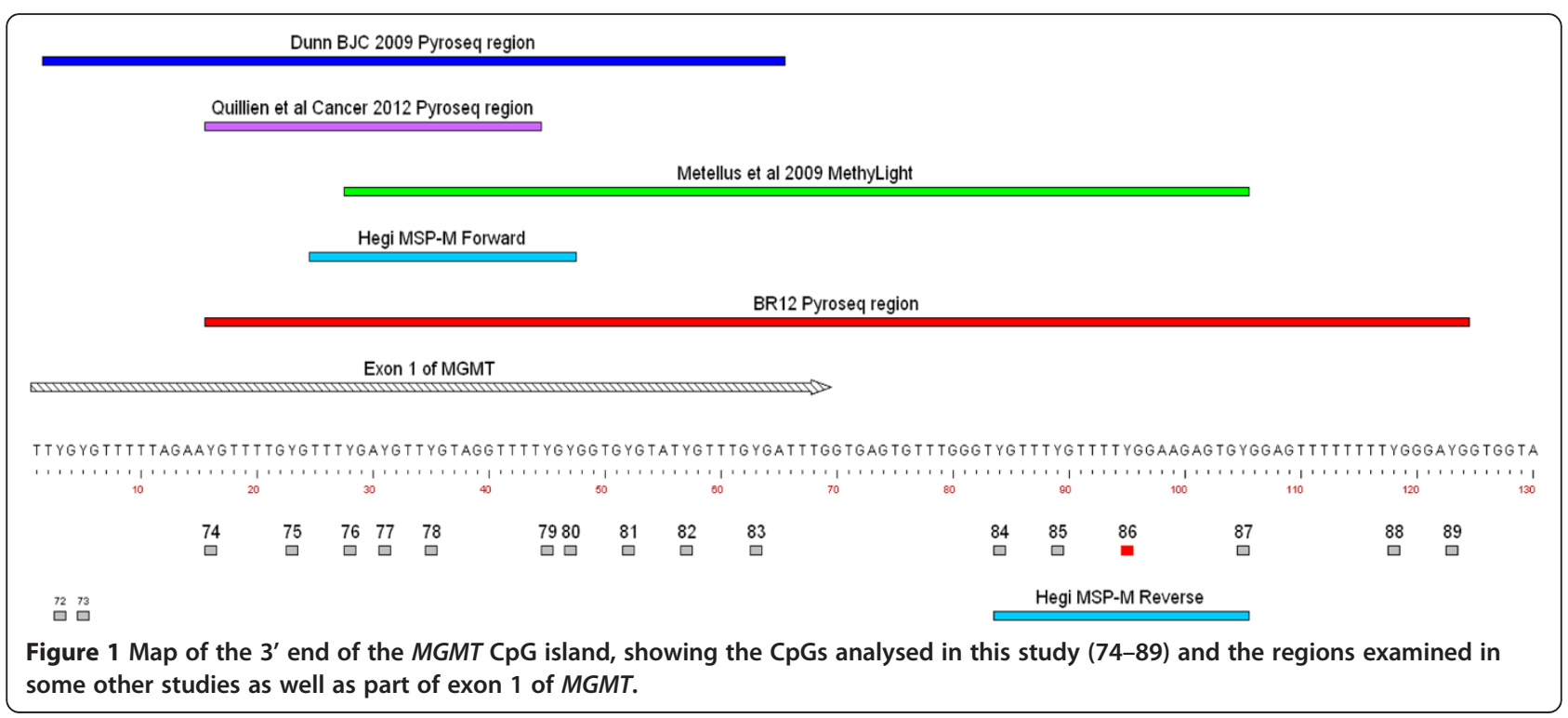


studies (low methylation $=<10 \%$, high $=\geq 10 \%$ ). Subsequent exploratory analyses looked at individual $\mathrm{CpG}$ data as continuous variables for their prognostic and predictive value using Cox regression survival models with fractional polynomials to allow for non-linear associations with survival [21]. The family of degree-one fractional polynomials (which include $\log (\mathrm{x})$ and $\mathrm{x}^{2}$ ) were used. To assess the robustness of the results, in the absence of an independent data set, bootstrap resampling methods were used taking bootstrap samples with 100 replicates. These analyses were carried out in all patients, and repeated in the subset hemizygous for MGMT in whom methylation\% represents a single value rather than an average across both copies of the gene. They were again repeated in the GB patients only.

\section{Results}

Pathological review and access to formalin fixed paraffin embedded tissue

Of 447 patients randomised into BR12, sections or blocks containing tumour were received from 354 (79\%). The two major reasons why tumour tissue was not available for the translational study were: a) consent for this part of the trial not obtained or refused (39 patients; $9 \%$ of all cases) and b) Histopathology Departments declining to release or unable to retrieve tissue (48 cases; $11 \%$ of all cases).

Material sufficient for central pathology review and some molecular analysis was possible on 314 patients (87\% of patients with material, $70 \%$ of randomised patients). Five patients were deemed ineligible, 3 gliosarcomas have been included among the glioblastomas. In cases that had been re-operated and where there were multiple specimens $(n=8)$ some of whom showed progression, the first WHO grade III or IV was used to determine tumour grade in that patient. Of the 309 eligible cases from whom material was received, successful analysis for aCGH, MGMT methylation and IDH1/2 mutation was possible in 267, 281 and 282 cases respectively; successful analysis for all parts of the study was possible in 236 (53\% of randomised patients). Comprehensive analysis of exons 4-10 of TP53 was, however, only successful in 82 cases, while incomplete data were obtained in a further 186 .

\section{Representativeness of samples}

Patient characteristics and survival in patients with and without tumour samples sufficient for analysis of MGMT methylation and $I D H 1 / 2$ respectively were compared; the only systematic difference was the extent of resection at initial surgery, the proportion of patients with biopsy alone being higher in the group for whom MGMT methylation and IDH1/2 analysis was not possible (e.g. $39 \%$ vs. $18 \%$ in patients where methylation analysis was possible). However, there was no clear difference in overall survival between the patients who were included in the MGMT methylation analyses and those who were not $(\mathrm{HR}=0.97,95 \% \mathrm{CI}(0.78-1.21))$ and this result was similar for the IDH1 analysis $(\mathrm{HR}=0.86,95 \% \mathrm{CI}$ (0.69-1.07)).

\section{Frequency of copy number abnormalities}

Array CGH was successful in 267 eligible cases including 6 AOA, 36 AA and 225 GB. Copy number abnormalities are tabulated by tumour type/grade in Table 1 .

Total loss of one copy of each of $1 p$ and $19 q$ was seen in only 4 patients overall $1.5 \%, 95 \% \mathrm{CI}(0.4-3.8 \%)$ and included 1/6 AOAs, 1/36 AAs and 2/225 GBs. The AOA and the AA with total loss of one copy of each of $1 \mathrm{p}$ and $19 \mathrm{q}$ both also had a mutation of IDH1 (R132H) and marked methylation of all the 16 MGMT CpGs assayed. The data set for the 2 GBs was not complete. The other common region lost on $1 \mathrm{p}$ was limited to the $1 \mathrm{p} 36$ region. Hemizygous loss of this region was seen in $4 / 36$ AAs $11.1 \%$, 95\% CI (3.1 - 26.1\%) and 49/225 GBs 21.8\%, $95 \%$ CI (16.6 - 27.7\%) with a further 6 GBs (2.7\%) showing homozygous deletion of $1 \mathrm{p} 36$.

Copy number of the following genes were documented on the tailored array by the use of specific probes (EGFR, CDKN2A, CDKN2B, p14ARF, MDM2, CDK4, $R B 1$ and $P D G F R A)$. Amplification of the $4 \mathrm{q} 12$ region encompassing the PDGFRA gene was seen only in anaplastic astrocytomas $(3 / 36 ; 8 \%)$ and glioblastomas $(14 / 225$; $6 \%$ ). The following copy number abnormalities were all most common in the glioblastomas; polysomy of chromosome 7 (64\%); focal amplification of the region encompassing the EGFR receptor gene (44\%); homozygous deletion of the $9 \mathrm{p} 21.3$ region encompassing the $C D K N 2 A / 14^{A R F}$ and CDKN2B genes (32\%); monosomy chromosome 10 (65\%); amplifications of 12q14-15 region encompassing the CDK4 (11\%) and MDM2 (9\%) genes; loss of the region encompassing the $R B 1$ gene $(27 \%)$; and trisomy 19 (21\%).

\section{IDH1 and IDH2 mutation analysis}

IDH1 mutation analysis identified mutation of codon 132 in 5/6 (83\%) AOA, 36/43 (84\%) AA and 40/232 (18\%) of the successfully analysed GB in the series (Table 1). IDH2 was analysed in all cases where no mutations were found in IDH1 but was found in only 1/232 GB patients. Survival by $I D H 1 / 2$ mutation status is shown in Figure 2.

\section{Mutation analysis of TP53}

Mutation analysis of exons 4-10 of TP53 was attempted in 268 cases. This was not successful for all exons in a significant number of cases due to limited amount of template. However, the 82 cases with complete data showed 
Table 1 Frequency of genetic abnormalities by tumour type

\begin{tabular}{|c|c|c|c|c|c|c|c|c|}
\hline & \multicolumn{8}{|c|}{ Tumour grade } \\
\hline & \multicolumn{2}{|c|}{$A O A$} & \multicolumn{2}{|c|}{$A A$} & \multicolumn{2}{|c|}{ GB } & \multicolumn{2}{|c|}{ Total } \\
\hline & $\mathrm{N}$ & $\%$ & $\mathrm{~N}$ & $\%$ & $\mathbf{N}$ & $\%$ & $N$ & $\%$ \\
\hline \multicolumn{9}{|l|}{ Chromosome 1 status } \\
\hline Normal copy number & 3 & $50 \%$ & 26 & $72 \%$ & 127 & $56 \%$ & 156 & $58 \%$ \\
\hline Trisomy & 0 & $0 \%$ & 0 & $0 \%$ & 4 & $2 \%$ & 4 & $1 \%$ \\
\hline Monosomy & 0 & $0 \%$ & 0 & $0 \%$ & 0 & $0 \%$ & 0 & $0 \%$ \\
\hline Any other abnormality & 3 & $50 \%$ & 10 & $28 \%$ & 94 & $42 \%$ & 107 & $40 \%$ \\
\hline \multicolumn{9}{|l|}{$1 p$ status } \\
\hline Normal copy number & 4 & $67 \%$ & 28 & $78 \%$ & 150 & $67 \%$ & 182 & $68 \%$ \\
\hline Loss of 1 copy & 1 & $17 \%$ & 1 & $3 \%$ & 2 & $1 \%$ & 4 & $1 \%$ \\
\hline Any other abnormality & 1 & $17 \%$ & 7 & $19 \%$ & 73 & $32 \%$ & 81 & $30 \%$ \\
\hline \multicolumn{9}{|l|}{$1 \mathrm{p} 36$ status } \\
\hline Normal copy number & 4 & $67 \%$ & 31 & $86 \%$ & 161 & $72 \%$ & 196 & $73 \%$ \\
\hline Loss of 1 copy & 1 & $17 \%$ & 4 & $11 \%$ & 49 & $22 \%$ & 54 & $20 \%$ \\
\hline Loss of both regions & 0 & $0 \%$ & 0 & $0 \%$ & 6 & $3 \%$ & 6 & $2 \%$ \\
\hline Any other abnormality & 1 & $17 \%$ & 1 & $3 \%$ & 9 & $4 \%$ & 11 & $4 \%$ \\
\hline \multicolumn{9}{|l|}{ Other abnormality } \\
\hline No & 4 & $67 \%$ & 28 & $78 \%$ & 160 & $71 \%$ & 192 & $72 \%$ \\
\hline Yes & 2 & $33 \%$ & 8 & $22 \%$ & 65 & $29 \%$ & 75 & $28 \%$ \\
\hline \multicolumn{9}{|l|}{ Chromosome 10 status } \\
\hline Normal copy number & 4 & $67 \%$ & 14 & $39 \%$ & 24 & $11 \%$ & 42 & $16 \%$ \\
\hline Monosomy & 0 & $0 \%$ & 4 & $11 \%$ & 146 & $65 \%$ & 150 & $56 \%$ \\
\hline 10q partial deletion & 2 & $33 \%$ & 14 & $39 \%$ & 45 & $20 \%$ & 61 & $23 \%$ \\
\hline Any other abnormality & 0 & $0 \%$ & 4 & $11 \%$ & 10 & $4 \%$ & 14 & $5 \%$ \\
\hline \multicolumn{9}{|l|}{ PTEN } \\
\hline Normal copy number & 6 & $100 \%$ & 26 & $72 \%$ & 54 & $24 \%$ & 86 & $32 \%$ \\
\hline Hemizygous deletion & 0 & $0 \%$ & 10 & $28 \%$ & 162 & $72 \%$ & 172 & $64 \%$ \\
\hline Homozygous deletion & 0 & $0 \%$ & 0 & $0 \%$ & 9 & $4 \%$ & 9 & $3 \%$ \\
\hline \multicolumn{9}{|l|}{ MGMT } \\
\hline Normal copy number & 4 & $67 \%$ & 15 & $42 \%$ & 28 & $12 \%$ & 47 & $18 \%$ \\
\hline Hemizygous deletion & 2 & $33 \%$ & 21 & $58 \%$ & 196 & $87 \%$ & 219 & $82 \%$ \\
\hline \multirow[t]{2}{*}{ Homozygous deletion } & 0 & $0 \%$ & 0 & $0 \%$ & 1 & $0 \%$ & 1 & $0 \%$ \\
\hline & 6 & $100 \%$ & 36 & $100 \%$ & 225 & $100 \%$ & 267 & $100 \%$ \\
\hline \multicolumn{9}{|l|}{ Chromosome 7 status } \\
\hline Normal copy number & 3 & $50 \%$ & 22 & $61 \%$ & 36 & $16 \%$ & 61 & $23 \%$ \\
\hline Trisomy/polysomy & 0 & $0 \%$ & 2 & $6 \%$ & 143 & $64 \%$ & 145 & $54 \%$ \\
\hline Monosomy & 0 & $0 \%$ & 0 & $0 \%$ & 1 & $0 \%$ & 1 & $0 \%$ \\
\hline Any other abnormality & 3 & $50 \%$ & 12 & $33 \%$ & 45 & $20 \%$ & 60 & $22 \%$ \\
\hline \multicolumn{9}{|l|}{ Chromosome 19 status } \\
\hline Normal copy number & 4 & $67 \%$ & 26 & $72 \%$ & 135 & $60 \%$ & 165 & $62 \%$ \\
\hline Trisomy & 0 & $0 \%$ & 4 & $11 \%$ & 48 & $21 \%$ & 52 & $19 \%$ \\
\hline Monosomy & 0 & $0 \%$ & 0 & $0 \%$ & 4 & $2 \%$ & 4 & $1 \%$ \\
\hline Any other abnormality & 2 & $33 \%$ & 6 & $17 \%$ & 38 & $17 \%$ & 46 & $17 \%$ \\
\hline
\end{tabular}


Table 1 Frequency of genetic abnormalities by tumour type (Continued)

\begin{tabular}{|c|c|c|c|c|c|c|c|c|}
\hline \multicolumn{9}{|l|}{$19 q$ status } \\
\hline Normal copy number & 4 & $67 \%$ & 27 & $75 \%$ & 139 & $62 \%$ & 170 & $64 \%$ \\
\hline Loss of 1 copy & 1 & $17 \%$ & 1 & $3 \%$ & 2 & $1 \%$ & 4 & $1 \%$ \\
\hline Any other abnormality & 1 & $17 \%$ & 8 & $22 \%$ & 84 & $37 \%$ & 93 & $35 \%$ \\
\hline \multicolumn{9}{|l|}{$19 q 13$ status } \\
\hline Normal copy number & 4 & $67 \%$ & 27 & $75 \%$ & 139 & $62 \%$ & 170 & $64 \%$ \\
\hline Loss of 1 copy & 0 & $0 \%$ & 3 & $8 \%$ & 20 & $9 \%$ & 23 & $9 \%$ \\
\hline Any other abnormality & 2 & $33 \%$ & 6 & $17 \%$ & 66 & $29 \%$ & 74 & $28 \%$ \\
\hline \multicolumn{9}{|l|}{ EGFR Amplification } \\
\hline No & 6 & $100 \%$ & 32 & $89 \%$ & 125 & $56 \%$ & 163 & $61 \%$ \\
\hline Yes ( $>4$ copies) & 0 & $0 \%$ & 4 & $11 \%$ & 100 & $44 \%$ & 104 & $39 \%$ \\
\hline \multicolumn{9}{|l|}{$C D K N 2 A / p 14^{A R F}$} \\
\hline Normal copy number & 4 & $67 \%$ & 24 & $67 \%$ & 87 & $39 \%$ & 115 & $43 \%$ \\
\hline Hemizygous deletion & 2 & $33 \%$ & 11 & $31 \%$ & 67 & $30 \%$ & 80 & $30 \%$ \\
\hline Homozygous deletion & 0 & $0 \%$ & 1 & $3 \%$ & 71 & $32 \%$ & 72 & $27 \%$ \\
\hline \multicolumn{9}{|l|}{ MDM2 Amplification } \\
\hline No & 6 & $100 \%$ & 34 & $94 \%$ & 205 & $91 \%$ & 245 & $92 \%$ \\
\hline Yes ( $>4$ copies) & 0 & $0 \%$ & 2 & $6 \%$ & 20 & $9 \%$ & 22 & $8 \%$ \\
\hline \multicolumn{9}{|l|}{ CDK4 amplification } \\
\hline No & 6 & $100 \%$ & 33 & $92 \%$ & 200 & $89 \%$ & 239 & $90 \%$ \\
\hline Yes ( $>4$ copies) & 0 & $0 \%$ & 3 & $8 \%$ & 25 & $11 \%$ & 28 & $10 \%$ \\
\hline \multicolumn{9}{|l|}{ PDGFRA amplification } \\
\hline No & 6 & $100 \%$ & 33 & $92 \%$ & 211 & $94 \%$ & 250 & $94 \%$ \\
\hline Yes (>4 copies) & 0 & $0 \%$ & 3 & $8 \%$ & 14 & $6 \%$ & 17 & $6 \%$ \\
\hline \multicolumn{9}{|l|}{ RB1 copy number } \\
\hline Normal & 5 & $100 \%$ & 31 & $86 \%$ & 164 & $73 \%$ & 200 & $75 \%$ \\
\hline Hemizygous deletion & 0 & $0 \%$ & 5 & $14 \%$ & 60 & $27 \%$ & 65 & $24 \%$ \\
\hline 3 copies & 0 & $0 \%$ & 0 & $0 \%$ & 1 & $0 \%$ & 1 & $0 \%$ \\
\hline \multicolumn{9}{|c|}{ TP53 mutation cases with complete dataset only } \\
\hline No & 2 & $40 \%$ & 4 & $40 \%$ & 43 & $64 \%$ & 49 & $60 \%$ \\
\hline Yes & 3 & $60 \%$ & 6 & $60 \%$ & 24 & $36 \%$ & 33 & $40 \%$ \\
\hline \multicolumn{9}{|l|}{ IDH1/IDH2 mutation } \\
\hline No & 1 & $17 \%$ & 7 & $16 \%$ & 191 & $82 \%$ & 199 & $71 \%$ \\
\hline Yes & 5 & $83 \%$ & 36 & $84 \%$ & 41 & $18 \%$ & 82 & $29 \%$ \\
\hline \multicolumn{9}{|l|}{ RB1 pathway } \\
\hline Normal & 3 & $60 \%$ & 19 & $53 \%$ & 52 & $23 \%$ & 74 & $28 \%$ \\
\hline Abnormal & 2 & $40 \%$ & 17 & $47 \%$ & 173 & $77 \%$ & 192 & $72 \%$ \\
\hline \multicolumn{9}{|l|}{ p53 pathway } \\
\hline Normal & 2 & $33 \%$ & 2 & $7 \%$ & 10 & $5 \%$ & 14 & $6 \%$ \\
\hline Abnormal & 4 & $67 \%$ & 26 & $93 \%$ & 181 & $95 \%$ & 211 & $94 \%$ \\
\hline \multicolumn{9}{|l|}{ MGMT Methylation } \\
\hline$<10 \%$ & 0 & $0 \%$ & 5 & $12 \%$ & 66 & $28 \%$ & 71 & $25 \%$ \\
\hline$\geq 10 \%$ & 6 & $100 \%$ & 36 & $88 \%$ & 168 & $72 \%$ & 210 & $75 \%$ \\
\hline
\end{tabular}




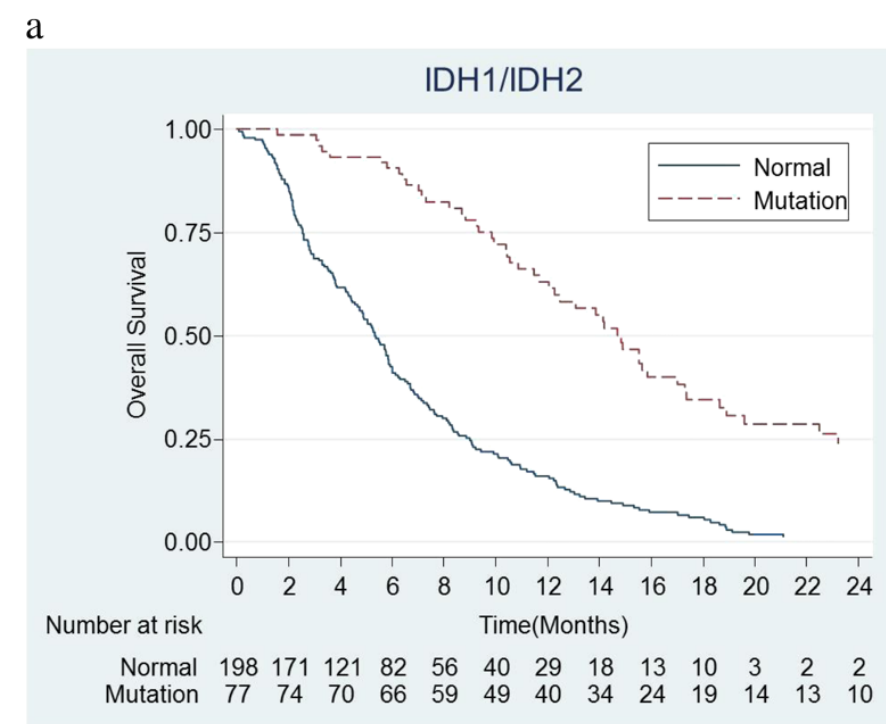

$\mathrm{b}$

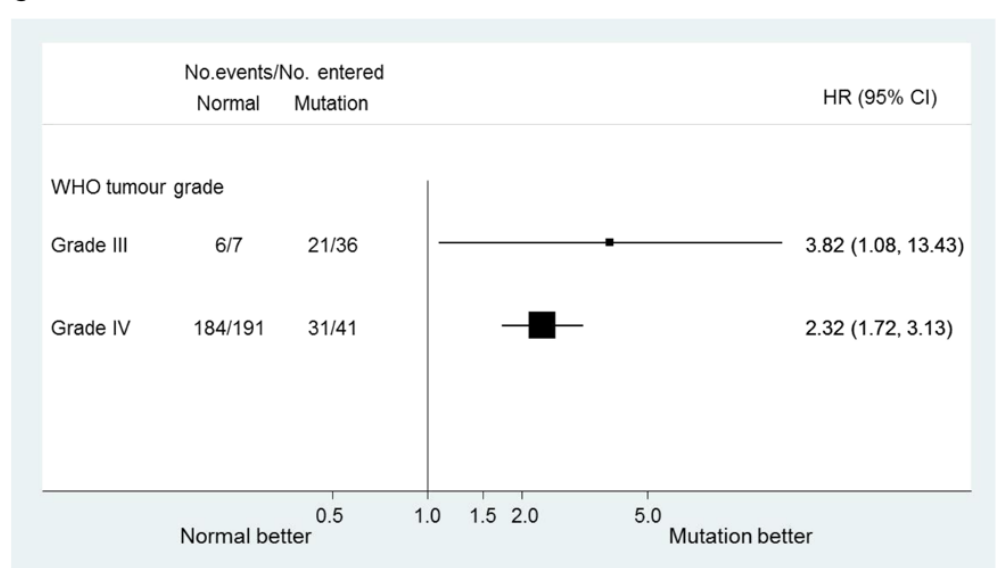

Figure 2 Survival by IDH1 mutation status. No IDH2 mutations were detected. Where DNA was available all cases without an IDH1 mutation were pyrosequenced for the common IDH2 mutations. a) All glioblastoma (GB) and anaplastic astrocytoma (AA) patients only. Kaplan-Meier plots of survival of patients who's tumours had wild type IDH1 alleles and those with one mutated allele. b) Assessing the prognostic value of IDH1 mutation in AA and GB shows that in both tumour types mutation is associated with a better outcome.

lower incidence of mutations in the GBs $(24 / 67 ; 36 \%)$ versus AA $(6 / 10 ; 60 \%)$ and AOA $(3 / 5 ; 60 \%)$ (see Table 1$)$ in accord with published data. In the 186 patients with incomplete data mutations were found in a further $41 \mathrm{~GB}$, $12 \mathrm{AA}$ and one AOA patient. However as the data set was incomplete it was not analysed further.

\section{The $\mathrm{p} 53$ and RB pathways}

In addition to the individual markers, a simple assessment of the status of the RB1 and p53 pathways was done (Table 1). Patients were considered to have a normal p53 pathway if CDKN2A/p14 ${ }^{A R f}, M D M 2$ and TP53 all had normal copy number, and to have an abnormal p53 pathway if any one of these had any abnormality (only copy number). Patients were determined to have a normal RB1 pathway if $C D K N 2 A, C D K 4$ and $R B 1$ had normal copy number, and to have an abnormal RB1 pathway if any one of these had any copy number abnormality. Disruption of each of these pathways was assessed for prognostic or predictive relevance (Table 2). The lack of comprehensive mutation data and methylation data for all of the genes in these pathways will result in an underestimate of their disruption.

\section{MGMT methylation data}

A genomic map showing the region of the MGMT CpG island analysed for methylation in this study by bisulfite modification followed by pyrosequencing and the corresponding $\mathrm{CpGs}$ studied by some others is shown in Figure $1[2,3,22,23]$. Initial analyses used the mean\% 
Table 2 Markers with independent prognostic value (Glioblastoma and Anaplastic Astrocytoma patients only)

\begin{tabular}{|c|c|c|c|c|}
\hline Marker & $N$ & HR $(95 \% \mathrm{Cl})$ & p-value & Overall $p$-value \\
\hline \multicolumn{5}{|l|}{ Chromosome 1} \\
\hline Normal & 153 & - & & 0.358 \\
\hline Trisomy & 4 & $0.92(0.29-2.92)$ & 0.885 & \\
\hline Any other abnormality & 104 & $1.22(0.93-1.59)$ & 0.157 & \\
\hline \multicolumn{5}{|l|}{$1 p$ status } \\
\hline Normal & 178 & - & & 0.828 \\
\hline Total loss of $1 p$ & 3 & $1.00(0.24-4.10)$ & 0.996 & \\
\hline Any other abnormality & 80 & $1.09(0.82-1.45)$ & 0.537 & \\
\hline \multicolumn{5}{|l|}{$1 \mathrm{p} 36$ status } \\
\hline Normal & 192 & - & & 0.646 \\
\hline Loss of 1 copy & 53 & $1.05(0.75-1.45)$ & 0.787 & \\
\hline Loss of both copies & 6 & $1.75(0.76-4.05)$ & 0.187 & \\
\hline Any other abnormality & 10 & $1.18(0.57-2.42)$ & 0.654 & \\
\hline \multicolumn{5}{|l|}{ Chromosome 7} \\
\hline Normal & 58 & - & & 0.029 \\
\hline Monosomy & 1 & $0.44(0.06-3.35)$ & 0.426 & \\
\hline Trisomy & 145 & $1.64(1.11-2.42)$ & 0.014 & \\
\hline Any other abnormality & 57 & $1.17(0.77-1.79)$ & 0.455 & \\
\hline \multicolumn{5}{|l|}{ Chromosome 10} \\
\hline Normal & 38 & - & & 0.006 \\
\hline Monosomy & 150 & $1.41(0.91-2.19)$ & 0.127 & \\
\hline 10q partial deletion & 59 & $0.76(0.48-1.21)$ & 0.241 & \\
\hline Any other abnormality & 14 & $1.24(0.58-2.65)$ & 0.583 & \\
\hline \multicolumn{5}{|l|}{ PTEN } \\
\hline Normal & 80 & - & & 0.001 \\
\hline Hemizygous deletion & 172 & $1.85(1.32-2.60)$ & $<0.001$ & \\
\hline Homozygous deletion & 9 & $1.31(0.62-2.81)$ & 0.480 & \\
\hline \multicolumn{5}{|l|}{ MGMT } \\
\hline Normal & 43 & - & & 0.776 \\
\hline Hemizygous deletion & 217 & $1.05(0.72-1.54)$ & 0.797 & \\
\hline Homozygous deletion & 1 & $2.22(0.30-16.56)$ & 0.438 & \\
\hline \multicolumn{5}{|l|}{ Chromosome 19} \\
\hline Normal & 161 & - & & 0.565 \\
\hline Monosomy & 4 & $1.91(0.69-5.25)$ & 0.210 & \\
\hline Trisomy & 52 & $1.14(0.82-1.60)$ & 0.442 & \\
\hline Any other abnormality & 44 & $0.95(0.66-1.36)$ & 0.772 & \\
\hline \multicolumn{5}{|l|}{$19 q$ status } \\
\hline Normal & 166 & - & & 0.754 \\
\hline Total loss of 19q & 3 & $1.10(0.27-4.55)$ & 0.898 & \\
\hline Any other abnormality & 92 & $1.11(0.84-1.47)$ & 0.454 & \\
\hline \multicolumn{5}{|l|}{ 19q13 status } \\
\hline Normal & 166 & - & & 0.643 \\
\hline Loss of 1 copy & 23 & $0.99(0.60-1.62)$ & 0.968 & \\
\hline Any other abnormality & 72 & $1.15(0.85-1.55)$ & 0.355 & \\
\hline
\end{tabular}


Table 2 Markers with independent prognostic value (Glioblastoma and Anaplastic Astrocytoma patients only) (Continued)

\begin{tabular}{|c|c|c|c|c|}
\hline \multicolumn{5}{|l|}{$E G F R$} \\
\hline Normal & 157 & - & & 0.013 \\
\hline Amplified & 104 & $1.42(1.08-1.87)$ & 0.013 & \\
\hline \multicolumn{5}{|l|}{ CDKN2A } \\
\hline Normal & 111 & - & & 0.771 \\
\hline Hemizygous deletion & 78 & $1.09(0.79-1.51)$ & 0.587 & \\
\hline Homozygous deletion & 72 & $1.12(0.80-1.58)$ & 0.500 & \\
\hline \multicolumn{5}{|l|}{ MDM2 } \\
\hline Normal & 239 & - & & 0.591 \\
\hline Amplified & 22 & $1.13(0.72-1.78)$ & 0.586 & \\
\hline \multicolumn{5}{|l|}{ CDK4 } \\
\hline Normal & 233 & - & & 0.083 \\
\hline Amplified & 28 & $1.46(0.97-2.21)$ & 0.070 & \\
\hline \multicolumn{5}{|l|}{ PDGFRA } \\
\hline Normal & 244 & - & & 0.998 \\
\hline Amplified & 17 & $1.00(0.60-1.68)$ & 0.997 & \\
\hline \multicolumn{5}{|l|}{ Chromosome 13} \\
\hline Normal & 184 & - & & 0.760 \\
\hline Monosomy & 37 & $1.15(0.79-1.68)$ & 0.460 & \\
\hline Trisomy & 1 & $0.86(0.12-6.34)$ & 0.886 & \\
\hline Partial deletion & 28 & $1.34(0.85-2.11)$ & 0.207 & \\
\hline Any other abnormality & 11 & $1.10(0.53-2.28)$ & 0.808 & \\
\hline \multicolumn{5}{|l|}{ RB1 gene status } \\
\hline Normal & 195 & - & & 0.469 \\
\hline Hemizygous deletion & 65 & $1.22(0.89-1.66)$ & 0.221 & \\
\hline Homozygous deletion & 1 & $0.86(0.12-6.26)$ & 0.878 & \\
\hline \multicolumn{5}{|l|}{ RB1 pathway } \\
\hline Normal & 71 & - & & 0.061 \\
\hline Abnormal & 190 & $1.35(0.98-1.87)$ & 0.066 & \\
\hline \multicolumn{5}{|l|}{ TP53 mutation } \\
\hline No & 47 & - & & 0.296 \\
\hline Yes & 83 & $0.80(0.53-1.21)$ & 0.293 & \\
\hline \multicolumn{5}{|l|}{ p53 pathway } \\
\hline Normal & 12 & - & & 0.265 \\
\hline Abnormal & 207 & $1.46(0.73-2.91)$ & 0.289 & \\
\hline \multicolumn{5}{|l|}{ IDH1 } \\
\hline Normal & 198 & - & & $<0.001$ \\
\hline Mutation & 77 & $0.38(0.26-0.56)$ & $<0.001$ & \\
\hline \multicolumn{5}{|l|}{ MGMT methylation } \\
\hline$<10 \%$ & 71 & - & & $<0.001$ \\
\hline$\geq 10 \%$ & 204 & $0.45(0.34-0.60)$ & $<0.001$ & \\
\hline
\end{tabular}

methylation across all $16 \mathrm{CpGs}$ to derive a single value per patient, and classified those with $<10 \%$ as low/ unmethylated and those $\geq 10 \%$ as high/methylated. This was based on the approach taken by Dunn et al. [22] and the data reported by Malley et al. [19] and examination of Kaplan Meier survival plots with methylation grouped by $10 \%$ intervals supported this approach (Figure 3) showing no evidence of a consistent linear 


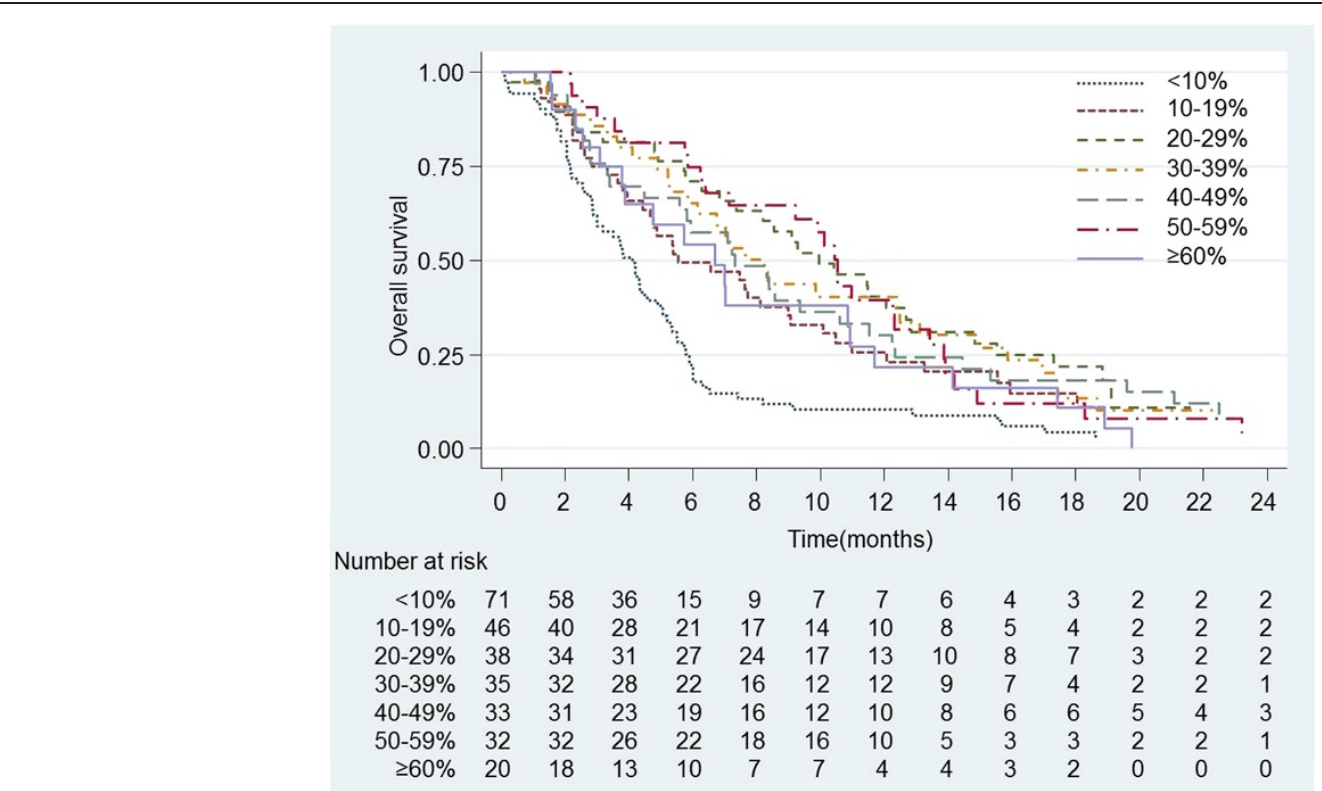

Figure 3 Kaplan-Meier plot of survival of all patients with anaplastic astrocytomas and glioblastomas by percentage methylation averaged over the $16 \mathrm{CpGs}$ analysed. Note that cases with average methylation levels of less than $10 \%$ differ markedly from those with greater than $10 \%$ but increasing levels of methylation do not seem to have much impact on the survival curves.

trend towards increased survival with increasing levels of methylation. The 6 cases where there were specimens with complete $\mathrm{CpG}$ data from two operations showed relatively large variance in mean\% methylation at each $\mathrm{CpG}$ but in no case did the mean cross the $10 \%$ threshold, so all tumours categorised as having methylation of MGMT at the first operation ( $5 / 6$ cases) were found to be methylated at the second operation and visa versa.

\section{Exploratory analyses of individual $\mathrm{CpG}$ methylation data}

The best way to use the individual CpG methylation \%s is not known, but a simple average across all 16 gives each CpG equal weight, and this may not be optimal. Examination of the correlation coefficients for each CpG with each of the other CpGs showed them all to be highly correlated (data not shown) which suggests that the prognostic value of methylation could be retained using data from fewer CpGs. Each CpG was therefore examined individually for its prognostic importance in Cox regression models which retained the baseline clinical factors and tumour grade (AA vs GB).

Analysing all eligible AA and GB patients $(n=269)$, irrespective of the MGMT gene status, only 2 of the CpGs were retained in the prognostic model, CpG 85 and 87 both with natural $\log$ transformations which suggested that a binary cut-off point at 5-10\% would also be appropriate. Using bootstrap resampling to assess the robustness of the model confirmed the importance of CpG 85 (retained in $87 \%$ of samples at a significance level of $<0.01$ ) but indicated slightly more uncertainty for CpG 87 (retained in $79 \%$ of samples).
Analysing the MGMT hemizygous patients only $(\mathrm{n}=203)$, a different model emerged with CpGs 75, 76 and 88 retained. However this model proved unstable using the bootstrap resampling with none of these CpGs retained in more than $60 \%$ of the samples. Repeating these analyses in GB patients only, the MGMT hemizygous subgroup again did not provide robust results but retained CpG 75 in $67 \%$ of samples.

In view of the lack of stability of the models using individual CpG data, the mean value across all CpGs was included in the subsequent prognostic and predictive models.

\section{Clinical correlations}

The association between each of the markers and the baseline clinical variables was assessed. As expected, the majority showed a clear association with tumour grade (Table 1) in most cases GB tumours had higher rates of abnormalities but 2 clear exceptions to this were TP53 and IDH1 mutations where the reverse was true. Analysis of the RB1 pathway showed an increased incidence of abnormalities (as defined above) from $47 \%$ in AA to $77 \%$ in GB while abnormalities of the TP53 pathway were present in $93 \%$ of $\mathrm{AA}$ and $95 \%$ of GB (the latter were generally not due to TP53 mutations). With respect to other clinical prognostic factors, normal PTEN copy number, IDH1/2 mutation, TP53 mutation and loss of 1 copy of $19 \mathrm{q} 13$ were all associated with younger age, while EGFR amplification, monosomy chromosome 10, homozygous deletion of $C D K N 2 A / p 14^{A R F}$, and an abnormal RB1 pathway were all associated with increased age. 
EGFR amplification and homozygous deletion of PTEN were associated with poorer performance status and IDH1 mutation with better performance status.

There was an association between IDH1 mutations and MGMT methylation (higher IDH1 mutation rates in methylated tumours) across all tumour grades; this was statistically significant (Fisher's exact test, $\mathrm{p}<0.01$ ) for both AOA/AA and GB patients, but was most marked in the AOAs and AAs. Among the 6 AOA tumours 5/6 had IDH1 mutations, and all 6 were judged to show methylation of MGMT Considering only tumours where we had results from both MGMT and IDH1/2 assays, among the AA 34/39 were judged to have methylation of MGMT and 31 of these 34 (91\%) had IDH1 mutations. Only $1 / 5$ (20\%) AA without methylation of MGMT had an IDH1 mutation. Among the GBs with both results available $153 / 215$ were judged to show MGMT methylation of which 36/153 (24\%) had IDH1 mutations, while IDH1 mutations were present in only $1 / 62$ (2\%) GBs with no evidence of MGMT methylation. Similarly, there was an association between $I D H 1$ mutations, PTEN status and tumour grade; a higher proportion of AA/AOA tumours (36/41, 75\%) were PTEN normal vs 52/211 (25\%) GBs. However, for both groups the IDH1 mutation rate was higher in patients with normal copy number for PTEN (51/82, 62\%) than for PTEN hemi- or homozygous deleted cases $(17 / 169,10 \%)$, p $<0.001$.

\section{Prognostic markers}

In view of the clinical associations noted above, each of the potential markers was assessed first for its independent prognostic value in a Cox regression model which included the baseline clinical characteristics (age, WHO performance status, sex) as well as tumour grade (AA vs GB; the small group with AOA tumours was excluded from these analyses). Table 2 summarises the results of these analyses showing that, individually, chromosome 7 and chromosome 10 copy number, EGFR amplification, PTEN deletion, and mutated IDH1 was associated with better prognosis. However when all these factors were added to the base clinical model and a backwards stepwise selection carried out for the non-clinical variables, only IDH1 mutation retained independent statistical significance (Table 3, model 1), indicating that, after accounting for tumour grade, age, sex and performance status, IDH1 mutation was associated with better prognosis. In view of the small number of patients in some categories, it was not possible to look reliably at all possible interactions within the Cox model, however interaction between IDH1 mutation and tumour grade was specifically examined; Figure $2 \mathrm{~b}$ shows that, while IDH1 mutations were much more common in AA patients, they were also prognostic for survival, and associated with a similar $\mathrm{HR}$, in $\mathrm{GB}$ patients (interaction $\mathrm{p}>0.1$ ).
MGMT methylation (mean methylation $<10 \%$ vs $\geq 10 \%$ ) was then introduced to the prognostic model. It retained independent prognostic value (better prognosis associated with methylation) when added directly to the best previous model (clinical variables plus IDH1 mutation, see Table 3, model 2) and when included in the stepwise model selection alongside all the factors that had prognostic value independent of the clinical factors (Table 3, model 3). However in the latter case, PTEN copy number was retained in the model instead of $I D H 1$ mutation. When the analyses were repeated in $M G M T$ hemizygous patients, the final model (Table 3, model 4) again contained only the clinical variables, IDH1/2 mutation and MGMT methylation status.

\section{Predictive markers}

Each of the potential markers was assessed for their ability to predict benefit for temozolomide over PCV, and of 21-day over 5-day TMZ. No evidence to support a predictive role was found for any of the above markers with the heterogeneity $\mathrm{p}$ value $>0.1$ in all cases. The binary methylation variable was also assessed as a predictor of improved survival with TMZ over PCV and of 21-day TMZ over 5-day TMZ. The hazard ratio plots are shown in Figure 4 for all patients, and for the subset of patients with hemizygous deletion of the MGMT gene. While there was slightly greater evidence of interaction in the latter group (benefit to TMZ over PCV being greater in patients with higher methylation), there was no clear evidence that MGMT methylation was predictive of benefit to TMZ over PCV or of 21-day TMZ over 5-day TMZ. In keeping with the results of the main trial, patients with MGMT methylation showed a trend towards better survival on 5-day TMZ rather than 21-day.

\section{Discussion}

This study provides information on the incidence and prognostic significance of a range of biomarkers in patients with recurrent high-grade glioma in the setting of a randomised trial that also allows for the assessment of their potential predictive value. Although the study aimed to assess biomarkers in all tumour specimens, the practical reality, particularly in brain tumours and specifically high grade gliomas is that some samples are too small for analysis due to the limited amount of tissue which can be obtained by biopsy and the frequent presence of necrosis within the specimens. Nevertheless the formalin fixed paraffin embedded material, which should have been available from all patients who consented for the molecular part of the study, allowed for a whole range of modern techniques and provides a realistic picture of the status of a variety of biomarkers of importance in glial tumours. In addition there were no significant differences in the patient and disease characteristics, 
Table 3 Multivariate analyses

\begin{tabular}{|c|c|c|c|c|}
\hline \multirow[t]{2}{*}{ Factor } & \multicolumn{4}{|c|}{ HR $(95 \% \mathrm{Cl})(\mathrm{p}$ value to exclude from model) } \\
\hline & Model 1* (all pts) & Model 2* (all pts) & Model 3* (all pts) & Model $4 *$ (all pts) \\
\hline \multicolumn{5}{|l|}{ Fixed variables } \\
\hline Age (years) & $1.01(0.99,1.02)$ & $1.01(1.00,1.02)$ & $1.01(1.00,1.02)$ & $1.00(0.98,1.02)$ \\
\hline \multicolumn{5}{|l|}{ Tumour grade } \\
\hline III & 1 & 1 & 1 & 1 \\
\hline IV & $1.84(1.10,3.08)$ & $2.25(1.33,3.83)$ & $2.43(1.48,3.98)$ & $1.53(0.81,2.92)$ \\
\hline \multicolumn{5}{|l|}{ WHO Performance status } \\
\hline 0 & 1 & 1 & 1 & 1 \\
\hline 1 & $0.86(0.58,1.27)$ & $0.93(0.63,1.39)$ & $0.93(0.63,1.38)$ & $0.79(0.51,1.21)$ \\
\hline 2 & $1.42(0.93,2.17)$ & $1.63(1.06,2.53)$ & $1.62(1.05,2.50)$ & $1.39(0.87,2.22)$ \\
\hline 3 & $1.23(0.69,2.20)$ & $1.54(0.85,2.81)$ & $1.46(0.93,2.97)$ & $1.64(0.88,3.06)$ \\
\hline \multicolumn{5}{|l|}{ Gender } \\
\hline Male & 1 & 1 & 1 & 1 \\
\hline Female & $0.80(0.59,1.07)$ & $0.82(0.61,1.10)$ & $0.80(0.57,1.03)$ & $0.91(0.66,1.25)$ \\
\hline \multicolumn{5}{|c|}{ Additional independent factors } \\
\hline \multicolumn{5}{|l|}{ IDH1 } \\
\hline Normal & 1 & 1 & & 1 \\
\hline Mutated & $\begin{array}{l}0.45(0.29,0.67) \\
\quad(p<0.001)\end{array}$ & $\begin{array}{c}0.58(0.37,0.91) \\
\quad(p=0.015)\end{array}$ & & $\begin{array}{l}0.32(0.18,0.56) \\
\quad(P<0.001)\end{array}$ \\
\hline \multicolumn{5}{|l|}{ PTEN } \\
\hline Normal & & & 1 & \\
\hline Hemizygous deletion & & & $1.83(1.29,2.61)$ & \\
\hline Homozygous deletion & & & $\begin{array}{c}1.47(0.68,3.16) \\
P=0.003\end{array}$ & \\
\hline \multicolumn{5}{|l|}{ MGMT methylation } \\
\hline$<10 \%$ & & 1 & 1 & 1 \\
\hline$\geq 10 \%$ & & $\begin{array}{c}0.59(0.42,0.82) \\
P=0.002\end{array}$ & $\begin{array}{c}0.49(0.36,0.67) \\
(p<0.001)\end{array}$ & $\begin{array}{c}0.44(0.30,0.63) \\
\quad(p=0.002)\end{array}$ \\
\hline
\end{tabular}

*Model 1: mutation data only, final backwards stepwise selection model.

Model 2: addition of MGMT methylation status to Model 1.

Model 3: final backwards stepwise model including mutation data and MGMT methylation status.

Model 4: final backwards stepwise model including mutation data and MGMT methylation status, MGMT hemizygous deletion patients only.

treatment delivered and in outcome comparing the patients with assessable and unavailable tissue. All the specimens were micro-dissected to ensure that almost only tumour tissue was analysed, limiting the risk of normal DNA making the identification of genetic changes more difficult, and the results are therefore truly representative of glioma tissue.

It must be stressed that the molecular analyses were almost all carried out on tumour resected prior to radiotherapy and that the tumours could have changed molecularly at the recurrence that resulted in the patient being recruited to this trial. However, as discussed below, the $I D H$ mutation status and the MGMT methylation data from the tumour at presentation were still found to be of prognostic significance. In a small number of patients who were operated on a number of times (data not shown) it was possible to study a number of tumour specimens. In all cases both the IDH status and the MGMT methylation status remained constant despite an increase in $\mathrm{WHO}$ grade.

The frequencies of the chromosomal region and gene copy number abnormalities and the TP53 genes found by sequencing, are broadly in accord with published data [16,17,24-26], although the IDH1/2 mutation incidence among the glioblastomas (18\%) is higher than reported in other studies. This may indicate a selection bias in the cohort as patients were only eligible if they had a life expectancy greater than 1 month, were fit for chemotherapy with adequate hepatic, renal and haematological function [7]. These eligibility criteria would most likely exclude older patients who generally have primary glioblastomas without $I D H 1 / 2$ mutations. In addition a 


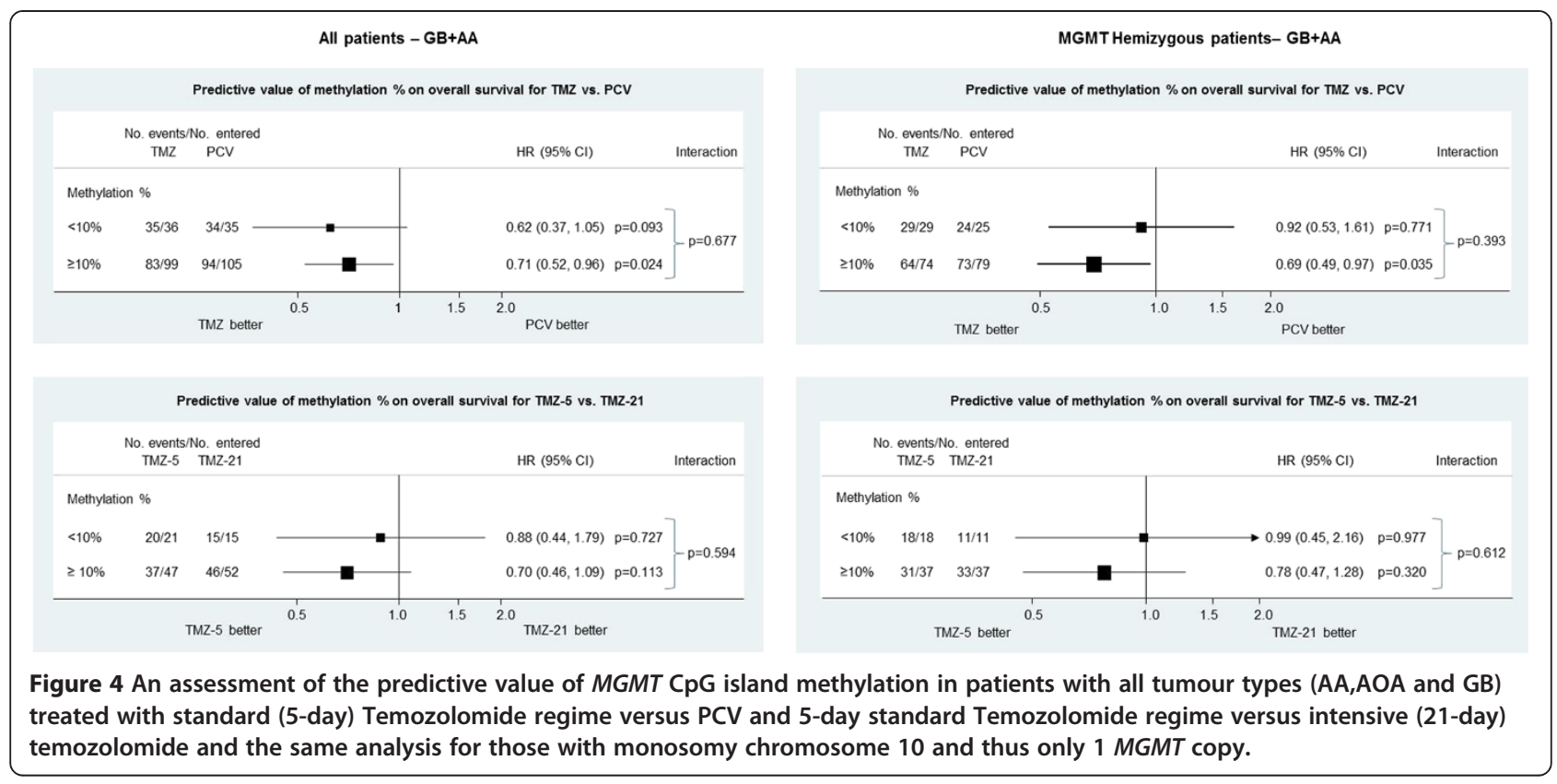

number of the glioblastomas were known secondary glioblastomas, having developed from astrocytomas or anaplastic astrocytomas. Tumour location was not documented in the trial. The sequencing of TP53 on formalin fixed paraffin embedded material proved difficult with a limited number of cases being comprehensively analysed, often due to limited template. Other examples of genetic abnormalities found at commonly reported levels include monosomy 10 found in $11 \%$ of the AA, but in $65 \%$ of the GB, EGFR amplification found to be present in none of the AOA, but in $11 \%$ of the AA and $44 \%$ of the GB and homozygous deletion of $C D K N 2 A / p 14^{A R F} / C D K N 2 B$ in $3 \%$ of AA; $32 \%$ of GB. [17,26-30]. The full range of biomarkers analysed was examined for prognostic significance for survival on univariate analysis; individually, chromosome 7 and chromosome 10 abnormalities, PTEN deletion, EGFR amplification, IDH1/2 mutation and MGMT methylation were all found to be of prognostic significance independently of clinical variables. However, only $I D H 1 / 2$ mutation (in one model replaced by PTEN status) and $M G M T$ methylation were independent prognostic factors for survival when tested on multivariate analysis including all clinical and molecular markers.

The study clearly demonstrates that in patients with recurrent high-grade glioma treated with either TMZ or PCV, IDH1/2 mutation and MGMT methylation levels are of prognostic value independent of tumour grade and of other clinical prognostic factors. While $I D H 1 / 2$ mutations were substantially more common in AA patients ( $84 \%$ vs $18 \%$ of GB), in both groups they were associated with significantly improved survival, with survival HRs of 3.82 (95\% CI 1.08, 13.43) and 2.32 (95\% CI $1.75,3.19)$ respectively. This corroborates many previous studies that have indicated the prognostic significance of mutation of one allele of either the IDH1 or IDH2 genes; patients with a mutation having a more favourable outcome [10]. The same is true of the methylation data presented [2]. It was also clear that there is a correlation between $I D H 1 / 2$ mutation and MGMT methylation and also IDH1/2 mutation and PTEN status which is present in both grade III tumours and primary glioblastomas [20].

Some studies of cultured cells have indicated that tumours with wild type TP53 in addition to those with MGMT methylation show increased sensitivity to alkylating agents, [31-34]. However, the incomplete data set in this study does not permit an analysis of this phenomenon.

CpG (cytosine-phosphate-Guanine) islands are genomic regions with a concentration of CpGs in the DNA sequence. They frequently encompass the promoter region and the first exon of genes and are intimately involved in control of expression. Extensive methylation of CpGs in such islands is generally associated with decreased expression. However, all of the CpGs in a particular island may not have the same impact on expression when methylated or unmethylated. Some may remain almost constantly methylated affecting negligibly gene expression. In the case of MGMT there are $98 \mathrm{CpGs}$ in the island and a number of studies have shown that while methylation of CpGs 1-25 and 51-73 have little impact on expression, methylation of CpGs 26-50 and 74-92 have [19,35]. Most studies have analysed the region 74-92 as is the case here $[1-3,22]$. The problem when using the findings for therapeutic decision-making is examining efficiently as many CpGs as are necessary to provide a clinically dependable and relevant answer for an individual patient. Some 
analytical methods examine only one $\mathrm{CpG}$ while others analyse varying numbers of CpGs (see [36-38] for reviews).

There are a number of analytic approaches to the assessment of MGMT methylation when data from individual CpGs is available. Our primary analyses replicated previous work, in taking an average value across all CpGs and dividing patients into those with low $(<10 \%)$ or high $(\geq 10 \%)$ methylation [22]. Based on this approach, we found MGMT methylation to be of independent prognostic value (over and above clinical factors and IDH1/2 mutation) but did not find clear evidence of a predictive effect in terms of distinguishing patients most likely to respond to TMZ over PCV. This was also the case when analyses were restricted to patients with hemizygous deletion of MGMT. While this might be expected given the presence of alkylating agents in both arms, it must also be acknowledged that power to detect modest interactions is low, and the potential for MGMT methylation to distinguish responders to TMZ over PCV, as it does for TMZ over no TMZ [2] cannot be excluded based on this study.

Reducing inherently continuous data, such as MGMT methylation, into binary (methylated/unmethylated) is not generally statistically efficient, and so in our exploratory analyses considering the individual CpGs we used the continuous data, and fitted models that allowed flexibility in the shape of any relationship between methylation\% and outcome beyond a simple linear relationship. Using all patients, irrespective of $M G M T$ copy number, CpGs 85 and 87 showed independent prognostic value (higher methylation conferring better prognosis) with best fit achieved using the natural log of methylation in each case; this can be interpreted as supporting a binary cut off as a sufficiently efficient way to summarise the data. However, when this analysis was repeated in MGMT hemizygous patients, an adequately stable model could not be found. Quillien et al. have presented data suggesting that CpG 77 is most significant [3] while Malley found mutation of CpG 89 to have the most marked effect on expression by a luciferase reporter construct [19].

Total loss of one copy of $1 \mathrm{p}$ and $19 \mathrm{q}$ is uncommon in anaplastic astrocytomas and glioblastomas, as was found in this study (1/36 AAs and 2/225 GB). However, hemizygous loss of $1 \mathrm{p} 36$ is much more common (AAs 11\%; GBs 22\%) and homozygous deletion of this area also occurs in some glioblastomas ( $3 \%$ in this study). However, while the incidence of losses in this area increased with malignancy grade, we found no evidence that this finding might represent a prognostic or a predictive biomarker.

In summary, in the largest randomised trial in chemonaïve patients with recurrent high grade glioma we were able to demonstrate the independent prognostic significance of IDH1/2 and MGMT methylation status, and potentially PTEN status, for survival. While individual
CpGs methylation data has the potential to replace overall mean values, we were not able to find a sufficiently stable model on which to base recommendations. The findings further support the argument that future trials in recurrent disease which are used as an indicator of efficacy of novel agents will need to stratify patients by all the known clinical prognostic factors and they must include $M G M T$ and $I D H 1 / 2$ status.

\section{Competing interests}

The authors declare that they have no competing interests.

\section{Acknowledgements}

Supported by Cancer Research UK grant number: C1475/A7690.

\section{Author details}

${ }^{1}$ Department of Pathology, Division of Molecular Histopathology, University of Cambridge, Cambridge, UK. ${ }^{2}$ MRC Clinical Trials Unit at UCL, University College London, London, UK. ${ }^{3}$ Department of Molecular and Clinical Cancer Medicine, University of Liverpool, Liverpool, UK. ${ }^{4}$ Division of Brain Tumor Translational Research, National Cancer Center Research Institute, Chuo-ku, Tokyo, Japan. ${ }^{5}$ Department of Histopathology, Addenbrooke's Hospital, Cambridge CB2 2QQ, UK.

\section{Received: 4 June 2014 Accepted: 4 June 2014}

Published: 20 June 2014

\section{References}

1. Stupp R, van den Bent MJ, Hegi ME (2005) Optimal role of temozolomide in the treatment of malignant gliomas. Curr Neurol Neurosci Rep 5(3):198-206

2. Hegi ME, Diserens AC, Gorlia T, Hamou MF, de Tribolet N, Weller M, Kros JM, Hainfellner JA, Mason W, Mariani L, Bromberg JE, Hau P, Mirimanoff RO, Cairncross JG, Janzer RC, Stupp R (2005) MGMT gene silencing and benefit from temozolomide in glioblastoma. N Engl J Med 352(10):997-1003, doi:10.1056/NEJMoa043331

3. Quillien V, Lavenu A, Karayan-Tapon L, Carpentier C, Labussiere M, Lesimple T, Chinot O, Wager M, Honnorat J, Saikali S, Fina F, Sanson M, Figarella-Branger D (2012) Comparative assessment of 5 methods (methylation-specific polymerase chain reaction, MethyLight, pyrosequencing, methylation-sensitive high-resolution melting, and immunohistochemistry) to analyze O6-methylguanine-DNA-methyltranferase in a series of 100 glioblastoma patients. Cancer 118(17):4201-4211, doi:10.1002/cncr.27392

4. Armstrong TS, Wefel JS, Wang M, Gilbert MR, Won M, Bottomley A, Mendoza TR, Coens C, Werner-Wasik M, Brachman DG, Choucair AK, Mehta M (2013) Net clinical benefit analysis of radiation therapy oncology group 0525: a phase III trial comparing conventional adjuvant temozolomide with dose-intensive temozolomide in patients with newly diagnosed glioblastoma. J Clin Oncol 31(32):4076-4084, doi:10.1200/ JCO.2013.49.6067

5. Wick W, Platten M, Meisner C, Felsberg J, Tabatabai G, Simon M, Nikkhah G, Papsdorf K, Steinbach JP, Sabel M, Combs SE, Vesper J, Braun C, Meixensberger J, Ketter R, Mayer-Steinacker R, Reifenberger G, Weller M, Society NOASGoN-oWGoGC (2012) Temozolomide chemotherapy alone versus radiotherapy alone for malignant astrocytoma in the elderly: the NOA-08 randomised, phase 3 trial. Lancet Oncol 13(7):707-715, doi:10.1016/S1470-2045(12)70164-X

6. Malmstrom A, Gronberg BH, Marosi C, Stupp R, Frappaz D, Schultz H, Abacioglu U, Tavelin B, Lhermitte B, Hegi ME, Rosell J, Henriksson R (2012) Temozolomide versus standard 6-week radiotherapy versus hypofractionated radiotherapy in patients older than 60 years with glioblastoma: the Nordic randomised, phase 3 trial. Lancet Oncol 13(9):916-926

7. Brada M, Stenning S, Gabe R, Thompson LC, Levy D, Rampling R, Erridge S, Saran F, Gattamaneni R, Hopkins K, Beall S, Collins VP, Lee SM (2010) Temozolomide versus procarbazine, lomustine, and vincristine in recurrent high-grade glioma. J Clin Oncol 28(30):4601-4608, doi:10.1200/JCO.2009.27.1932

8. Cairncross G, Wang M, Shaw E, Jenkins R, Brachman D, Buckner J, Fink K, Souhami L, Laperriere N, Curran W, Mehta M (2013) Phase III trial of 
chemoradiotherapy for anaplastic oligodendroglioma: long-term results of RTOG 9402. J Clin Oncol 31(3):337-343, doi:10.1200/JCO.2012.43.2674

9. van den Bent MJ, Brandes AA, Taphoorn MJ, Kros JM, Kouwenhoven MC, Delattre JY, Bernsen HJ, Frenay M, Tijssen CC, Grisold W, Sipos L, Enting RH, French PJ, Dinjens WN, Vecht CJ, Allgeier A, Lacombe D, Gorlia T, Hoang-Xuan K (2013) Adjuvant procarbazine, lomustine, and vincristine chemotherapy in newly diagnosed anaplastic oligodendroglioma: long-term follow-up of EORTC brain tumor group study 26951. J Clin Oncol 31(3):344-350, doi:10.1200/JCO.2012.43.2229

10. Hartmann C, Hentschel B, Wick W, Capper D, Felsberg J, Simon M, Westphal M, Schackert G, Meyermann R, Pietsch T, Reifenberger G, Weller M, Loeffler M, von Deimling A (2010) Patients with IDH1 wild type anaplastic astrocytomas exhibit worse prognosis than IDH1-mutated glioblastomas, and IDH1 mutation status accounts for the unfavorable prognostic effect of higher age: implications for classification of gliomas. Acta Neuropathol 120(6):707-718, doi:10.1007/s00401-010-0781-Z

11. Cairncross JG, Ueki K, Zlatescu MC, Lisle DK, Finkelstein DM, Hammond RR, Silver JS, Stark PC, Macdonald DR, Ino Y, Ramsay DA, Louis DN (1998) Specific genetic predictors of chemotherapeutic response and survival in patients with anaplastic oligodendrogliomas. J Natl Cancer Inst 90(19):1473-1479

12. van den Bent MJ, Looijenga LH, Langenberg K, Dinjens W, Graveland W, Uytdewilligen L, Sillevis Smitt PA, Jenkins RB, Kros JM (2003) Chromosomal anomalies in oligodendroglial tumors are correlated with clinical features. Cancer 97(5):1276-1284

13. Louis DN, Ohgaki H, Wiestler OD, Cavenee WK (eds) (2007) WHO Classification of Tumours of the Central Nervous System. WHO Organization Classification of Tumours, 4th edn. IARC, Lyon, France, Lyon

14. Jones DT, Ichimura K, Liu L, Pearson DM, Plant K, Collins VP (2006) Genomic analysis of pilocytic astrocytomas at $0.97 \mathrm{Mb}$ resolution shows an increasing tendency toward chromosomal copy number change with age. J Neuropathol Exp Neurol 65(11):1049-1058, doi:10.1097/01.jnen. 0000240465.33628 .87

15. Vogazianou AP, Chan R, Backlund LM, Pearson DM, Liu L, Langford CF, Gregory SG, Collins VP, Ichimura K (2010) Distinct patterns of 1p and 19q alterations identify subtypes of human gliomas that have different prognoses. Neuro Oncol 12(7):664-678, doi:10.1093/neuonc/nop075

16. Ichimura K, Pearson DM, Kocialkowski S, Backlund LM, Chan R, Jones DT, Collins VP (2009) IDH1 mutations are present in the majority of common adult gliomas but rare in primary glioblastomas. Neuro Oncol 11(4):341-347, doi:10.1215/15228517-2009-025

17. Ichimura K, Bolin MB, Goike HM, Schmidt EE, Moshref A, Collins VP (2000) Deregulation of the p14ARF/MDM2/p53 pathway is a prerequisite for human astrocytic gliomas with G1-S transition control gene abnormalities. Cancer Res 60(2):417-424

18. Jones DT, Kocialkowski S, Liu L, Pearson DM, Backlund LM, Ichimura K, Collins VP (2008) Tandem duplication producing a novel oncogenic BRAF fusion gene defines the majority of pilocytic astrocytomas. Cancer Res 68(21):8673-8677, doi:10.1158/0008-5472.CAN-08-2097

19. Malley DS, Hamoudi RA, Kocialkowski S, Pearson DM, Collins VP, Ichimura K (2011) A distinct region of the MGMT CpG island critical for transcriptional regulation is preferentially methylated in glioblastoma cells and xenografts. Acta Neuropathol 121(5):651-661, doi:10.1007/s00401-011-0803-5

20. Mulholland S, Pearson DM, Hamoudi RA, Malley DS, Smith CM, Weaver JM, Jones DT, Kocialkowski S, Backlund LM, Collins VP, Ichimura K (2011) MGMT CpG island is invariably methylated in adult astrocytic and oligodendroglial tumours with IDH1 or IDH2 mutations. J Int Cancer 135(5):1104-1113

21. Royston P, Sauerbrei W (2008) Multivariable Model-building: A prgamatic approach to regression analysis based on fractional polynomials for modelling continuous variables. John Wiley \& Sons, London

22. Dunn J, Baborie A, Alam F, Joyce K, Moxham M, Sibson R, Crooks D, Husband D, Shenoy A, Brodbelt A, Wong H, Liloglou T, Haylock B, Walker C (2009) Extent of MGMT promoter methylation correlates with outcome in glioblastomas given temozolomide and radiotherapy. Br J Cancer 101(1):124-131, doi:10.1038/sj.bjc.6605127

23. Metellus P, Coulibaly B, Nanni I, Fina F, Eudes N, Giorgi R, Barrie M, Chinot O, Fuentes S, Dufour H, Ouafik L, Figarella-Branger D (2009) Prognostic impact of O6-methylguanine-DNA methyltransferase silencing in patients with recurrent glioblastoma multiforme who undergo surgery and carmustine wafer implantation: a prospective patient cohort. Cancer 115(20):4783-4794, doi:10.1002/cncr.24546

24. Ekstrand AJ, James CD, Cavenee WK, Seliger B, Pettersson RF, Collins VP (1991) Genes for epidermal growth factor receptor, transforming growth factor alpha, and epidermal growth factor and their expression in human gliomas in vivo. Cancer Res 51(8):2164-2172

25. Reifenberger G, Reifenberger J, Ichimura K, Meltzer PS, Collins VP (1994) Amplification of multiple genes from chromosomal region 12q13-14 in human malignant gliomas: preliminary mapping of the amplicons shows preferential involvement of CDK4, SAS, and MDM2. Cancer Res 54(16):4299-4303

26. Collaborators CGARN (2008) Comprehensive genomic characterization defines human glioblastoma genes and core pathways. Nature 455(7216):1061-1068, doi:10.1038/nature07385

27. James CD, Carlbom E, Dumanski JP, Hansen M, Nordenskjold M, Collins VP, Cavenee WK (1988) Clonal genomic alterations in glioma malignancy stages. Cancer Res 48(19):5546-5551

28. Ichimura K, Vogazianou AP, Liu L, Pearson DM, Backlund LM, Plant K, Baird K, Langford CF, Gregory SG, Collins VP (2008) 1p36 is a preferential target of chromosome 1 deletions in astrocytic tumours and homozygously deleted in a subset of glioblastomas. Oncogene 27(14):2097-2108, doi:10.1038/sj.onc.1210848

29. Ekstrand AJ, Sugawa N, James CD, Collins VP (1992) Amplified and rearranged epidermal growth factor receptor genes in human glioblastomas reveal deletions of sequences encoding portions of the $\mathrm{N}$ - and/or C-terminal tails. Proc Natl Acad Sci U S A 89(10):4309-4313

30. Ekstrand AJ, Longo N, Hamid ML, Olson JJ, Liu L, Collins VP, James CD (1994) Functional characterization of an EGF receptor with a truncated extracellular domain expressed in glioblastomas with EGFR gene amplification. Oncogene 9(8):2313-2320

31. Bocangel DB, Finkelstein S, Schold SC, Bhakat KK, Mitra S, Kokkinakis DM (2002) Multifaceted resistance of gliomas to temozolomide. Clin Cancer Res 8(8):2725-2734

32. Hermisson M, Klumpp A, Wick W, Wischhusen J, Nagel G, Roos W, Kaina B, Weller M (2006) O6-methylguanine DNA methyltransferase and p53 status predict temozolomide sensitivity in human malignant glioma cells. J Neurochem 96(3):766-776, doi:10.1111/j.1471-4159.2005.03583.x

33. Russell SJ, Ye YW, Waber PG, Shuford M, Schold SC Jr, Nisen PD (1995) p53 mutations, O6-alkylguanine DNA alkyltransferase activity, and sensitivity to procarbazine in human brain tumors. Cancer 75(6):1339-1342

34. Xu GW, Mymryk JS, Cairncross JG (2005) Inactivation of p53 sensitizes astrocytic glioma cells to BCNU and temozolomide, but not cisplatin. J Neurooncol 74(2):141-149, doi:10.1007/s11060-004-6601-3

35. Bady P, Sciuscio D, Diserens AC, Bloch J, van den Bent MJ, Marosi C, Dietrich PY, Weller M, Mariani L, Heppner FL, McDonald DR, Lacombe D, Stupp R, Delorenzi M, Hegi ME (2012) MGMT methylation analysis of glioblastoma on the Infinium methylation BeadChip identifies two distinct $\mathrm{CpG}$ regions associated with gene silencing and outcome, yielding a prediction model for comparisons across datasets, tumor grades, and CIMP-status. Acta Neuropathol 124(4):547-560, doi:10.1007/s00401-012-1016-2

36. Weller M, Stupp R, Reifenberger G, Brandes AA, van den Bent MJ, Wick W, Hegi ME (2010) MGMT promoter methylation in malignant gliomas: ready for personalized medicine? Nat Rev Neurol 6(1):39-51, doi:10.1038/nrneurol.2009.197

37. Weller M, Stupp R, Hegi ME, van den Bent M, Tonn JC, Sanson M, Wick W, Reifenberger G (2012) Personalized care in neuro-oncology coming of age: why we need MGMT and $1 \mathrm{p} / 19 \mathrm{q}$ testing for malignant glioma patients in clinical practice. Neuro Oncol 14(Suppl 4):iv100-iv108, doi:10.1093/neuonc/nos206

38. Mason S, McDonald K (2012) MGMT testing for glioma in clinical laboratories: discordance with methylation analyses prevents the implementation of routine immunohistochemistry. J Cancer Res Clin Oncol 138(11):1789-1797, doi:10.1007/s00432-012-1312-1

doi:10.1186/2051-5960-2-68

Cite this article as: Collins et al:: Prognostic and predictive markers in recurrent high grade glioma; results from the BR12 randomised trial. Acta Neuropathologica Communications 2014 2:68. 